\title{
Isolation and Characterization of the Betaine Aldehyde Dehydrogenase Gene in Ophiopogon japonicus
}

\author{
Jun Liu ${ }^{\mathrm{a}}$, Huiming Zeng ${ }^{\mathrm{a}}$, Xue $\mathrm{Li}^{\mathrm{a}}$, Lixin $\mathrm{Xu}^{\mathrm{a}}$, Yingbo Wang ${ }^{\mathrm{a}}$, Wei Tang*,b and Liebao Han*,a \\ ${ }^{a}$ Institute of Turfgrass Science, Beijing Forestry University, Beijing 100083, China \\ ${ }^{b}$ Institute for Genome Sciences and Policy, Duke University, Durham 27708, USA
}

\begin{abstract}
Betaine aldehyde dehydrogenase (BADH) catalyzes the last step in the synthesis of the glycine betaine from choline. The BADH gene from turfgrass Ophiopogon japonicus has not been reported. In this study, we first isolated the full length cDNA of betaine aldehyde dehydrogenase gene $(O j B A D H)$ from $O$. japonicus using Reverse TranscriptasePolymerase Chain Reaction (RT-PCR) and Rapid Amplification of cDNA Ends (RACE) techniques. The OjBADH gene (GenBank accession number: DQ645888) has 1785 nucleotides with the 5' untranscribed region (UTR) of 63 nucleotides, 3' UTR of 219 nucleotides, and an open reading frame of 1503 nucleotides. This gene encodes a polypeptide of 500 amino acids. It shares a high homology with $B A D H$ genes of other Chenopodiaceae species. The putative protein includes a conservative region of phosphofructokinase, aldehyde dehydrogenase, and glutamy phosphoric acid reductase. Overexpression of $O j B A D H$ in transgenic tobacco plants demonstrated 2-2.5 folds increase of glycine betaine content and 60$85 \%$ increase of survival rate under salt tolerance. These results suggested that the $O$. japonicus BADH gene may be used to engineer plants for salt stress tolerance.
\end{abstract}

Keywords: Betaine aldehyde dehydrogenase, Choline, Gene cloning, Ophiopogon japonicas, Turfgrass.

\section{INTRODUCTION}

Betaine aldehyde dehydrogenase (BADH) catalyzes the last step (Fig. 1) in the synthesis of the osmoprotectant glycine betaine from choline [1-3]. Many bacteria, plants and animals accumulate glycine betaine under water or salt stress conditions $[1,4-6]$. BADH is a specific enzyme for production of glycine betaine [1, 7-9]. BADHs have been purified from several species [10-13]. The promoter of betaine aldehyde dehydrogenase gene has been isolated from Suaeda liaotungensis $\mathrm{K}$., and the analysis of the promoter sequence has revealed the existence of several putative cis-elements, such as TATA-box, CAAT-box, GC-motif, EIRE, MRE, WUN-motif, heat shock element (HSE) and ABRE [14]. Studies showed that BADHs from sugar beet [15] and humans $[16,17]$ also catalyze the oxidation of $\mathrm{v}$ aminoaldehydes such as 3-aminopropionaldehyde and 4aminobutyraldehyde, which are intermediates in putrescine and polyamine degradation.

Glycine betaine is an important osmoprotectant that is produced in response to salt and other osmotic stresses [1, 18-20]. Overexpression of $B A D H$ results in increase of tolerance of salt and osmotic stresses in many organisms [21-23]. Using Agrobacterium tumefaciens strain LBA4404 carrying a binary vector $\mathrm{pBin} 438$ and a leaf regeneration system, Jia et al. [20] demonstrated that overexpression of the $B A D H$ gene cloned from Atriplex hortensis in a salt-sensitive to

\footnotetext{
*Address correspondence to these authors at the Institute of Turfgrass Science, Beijing Forestry University, Beijing 100083, China; Tel: 010-919684-6507; Fax: 010-919-668-0795; E-mail: hanliebao@163.com

Institute for Genome Sciences and Policy, Duke University, Durham 27708, USA; Tel: +86-10-6233-7982; Fax: +86-10-6232-2089;

E-mail:wei.tang@duke.edu
}

mato cultivar, Bailichun, improved salt tolerance. Wu et al. [24] reported that the Suaeda liaotungensis betaine aldehyde dehydrogenase gene improved salt tolerance of transgenic maize mediated with minimum linear length of DNA fragment. After 15 days of treatment, $73.9-100 \%$ of the transgenic seedlings survived and grew well. However, more than $90 \%$ wild-type seedlings wilted and showed loss of chlorophyll. Only $8.9 \%$ of the wild-type plants survived but gradually died after salt stress [24].

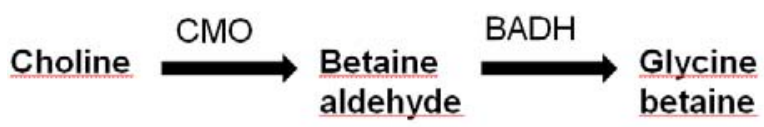

Fig. (1). Production of glycine betaine in higher plants. CMO, choline monooxygenase; BADH, betaine aldehyde dehydrogenase.

O. japonicus [(L.F) Ker-Gawl] is an evergreen perennial herb and a shade tolerant plant in the family of Liliaceae. $O$. japonicus has great stress tolerance and is adapted to a wide range of moisture conditions, and retains green color even in cold season. It is widely distributed and cultivated in many areas of China [9]. Environmental stress tolerance is one of the most important factors limiting $O$. japonicus growth and survival. Increasing environmental stress tolerance has been one of the major objectives in $O$. japonicus breeding programs. Cloning of the $B A D H$ gene from turfgrass $O$. japonicus has not been reported. Although many BADH genes have been isolated from other species [5, 11-13], it may not be functioning efficiently. To determine the phylogenetic relation of the BADH gene derived from O. japonicus with other available BADH genes and to identify the specific function of the $O$. japonicus BADH gene in environmental stress tolerance of turfgrass, we have cloned and character- 
ized the $O$. japonicus $B A D H$ gene in this investigation. We isolated a full-length cDNA sequence of $B A D H$ gene from O.japonicus through RT-PCR and RACE, and expressed the $O$. japonicus $B A D H$ gene in transgenic tobacco, which demonstrated the increased tolerance to salt. Our results suggested that the $O$. japonicus $B A D H$ gene may be used to engineer plants for salt and other osmotic stresses tolerance.

\section{MATERIALS AND METHODS}

\section{Plant Material}

O. japonicus plants were collected from Longtoushan Forestry Station in Hebei province and were planted in a laboratory nursery of Beijing Forestry University. E. coli (JM109), expression strains (E. coli BL21) and expression vector $[\mathrm{pET}-30 \mathrm{a}(+)]$ were preserved in $-80^{\circ} \mathrm{C}$, cloning vector (pMD-18T) was purchased from TAKARA company. The reagents and primers included Advantage ${ }^{\mathrm{TM}}$ RT-for-PCR Kit (TAKARA); BD SMART ${ }^{\mathrm{TM}}$ RACE cDNA Amplification Kit (CLONETECH); TIANgel Maxi Purification Kit, Taq DNA Polymerase, Pfu DNA Polymerase, and TRNzol Total RNA (Beijing TIANGEN); and Restriction endonucleases (NEB), DEPC (Promega). Primers were synthesized by Shanghai Sangon and other reagents for analysis were all made in China.

\section{Isolation of the $O J B A D H$ cDNA}

The total RNA was extracted from the leaves of oneyear-old plants by TRNzol RNA reagents. Using the total RNA as template, the first-strand cDNA was synthesized by Advantage $^{\text {TM }}$ RT-for-PCR Kit according to the manufacturer's protocols. Based on the cDNA sequences of Spinacia oleracea L., Beta vulgaris L., Atriplex hortensis Golosk., Hordeum vulgare L., Sorghum bicolor Pers, Amaranthus hypochondriacus L., Avicennia marina (Forsk.)Vierh., Suaeda liaotungensis Kitag., and Atriplex centralasiatica Iljin published in GenBank (http://www.ncbi.nlm.nih.gov/), higher homology region was selected and degenerate primers were designed as F1: 5'-CGHGCBATYGCTGCTAAG -3' and R1: 5'-TKGTACCANCCCCAYTGYTCAT-3'. The middle segment was obtained and sequenced by using the reverse transcribed cDNA as a template for the PCR amplification. Then, 5'RACE primer closed to the 5' terminus and 3'RACE primer close to the 3' terminus were designed as F2 5'-CAGAATCAAGGGTTTCCAGTTTAAC-3' and R2 5'CCCCGTTATTAGTAAAGGACA according to the results of sequencing, respectively. RACE was performed using the BD SMART ${ }^{\text {TM }}$ RACE cDNA Amplification Kit User Manual. The full-length sequence was obtained by stitching the three fragments from PCR amplification using DNAMAN software. Then, the specific primer at the end of 5' terminus F3 was designed as 5'-GCCAACGTAAGCCTATCGTT CCCATACCCG-3'. A pair of gene specific primers $F$ : 5' AACGGATCCATGGCGTTCCCAATTCCTGC-3'; R: 5' ACCGAGCTCTCAAGGAGCCTTGTACCATCCCC-3' were designed after the coding region was identified according to the complete sequence. The complete BADH cDNA was amplified using primers $F$ and $\mathrm{R}$. The PCR reaction was performed at $94^{\circ} \mathrm{C}$ for $4 \mathrm{~min}$, then at $94^{\circ} \mathrm{C}$ for $30 \mathrm{~s}, 59^{\circ} \mathrm{C} 30$ $\mathrm{s}, 72^{\circ} \mathrm{C}$ for $1.5 \mathrm{~min}$ for 30 cycles and $72^{\circ} \mathrm{C}$ for $10 \mathrm{~min}$. The coding fragment was amplified using these primers and the complete cDNA as a template and then ligated into pMD$18 \mathrm{~T}$ named as pMD-18T-MDBADH. Database searches for sequence homology and comparisons were performed with various web based analytical tools compiled at the website http://www.sdsc.edu/ResTools/. The phylogenetic tree was constructed using the ClustalW (http://www.ebi.ac.uk/ clustalw). We use ClustalW to create a multiple alignment of the protein sequences of the selected orthologs. Save the output file of the ClustalW output and run the program without changing the parameter settings to create the phylogenetic tree.

\section{Construction of the $O j B A D H$ cDNA Expression Vector}

The $1.785 \mathrm{~kb}$ fragment of the $O$. japonicus $B A D H$ gene was cloned into the expression vector pBI121 by following the protocol previously described [25] to generate expression vector pBI-OjBADH-GUS. To construct the $O j B A D H$ cDNA expression vector, the $O j B A D H$ cDNA was amplified using primer $\mathrm{R}$ and primer $\mathrm{F}$ from plasmid pMD-18T-OjBADH. The PCR product was purified and blunted with Klenow fragment. Plasmid pBI121 were digested with restriction endonucleases BamHI and blunted with Klenow fragment. After agarose gel electrophoresis, the long fragment (vector fragment from plasmid pBI121) and short fragment $(O j B A D H$ fragment amplified from pMD-18T-OjBADH) were purified and ligated. The vector has only one restriction endonucleases BamHI site in its T-DNA region. After transformation with competent cells, the positive clones were confirmed by PCR using primers $\mathrm{F}$ : 5'-AACGGATCCATG GCGTTCCCAATTCCTGC-3' ; R : 5'-ACCGAGCTCTC AAGGAGCCTTGTACCATCCCC-3'. The $O j B A D H$ DNA fragments in plant expression vector pBI-OjBADH-GUS (Fig. 5) were sequenced and the orientation of the $O j B A D H$ gene in pBI121 was determined by PCR and sequencing of PCR products before used for plant transformation.

\section{Expression of $\mathrm{OJBADH}$ in Tobacco}

For regeneration of $O j B A D H$ transgenic tobacco plants, plasmid pBI-OjBADH-GUS DNA were precipitated, adsorbed to gold particles $(1 \mu \mathrm{m})$, and delivered to target calli using a BioRad PDS-1000/He device by following the protocol (BioRad, USA). Plates containing the target tissues were placed $6 \mathrm{~cm}$ below the stopping mesh. Particle acceleration was done according to BioRad PDS-1000/He device at 1100 psi. Sixteen hours after particle bombardment, the calli were transferred to regeneration medium as previously [26].

\section{PCR and Southern Blot Analysis}

For molecular characterization of transgenic plants, genomic DNA from young leaves of putative transgenic plants (three-month-old) was extracted and used as template for PCR amplification. The primers were R2 and F2. The expected size of PCR product is $680 \mathrm{bp}$. The PCR reaction was performed at $94^{\circ} \mathrm{C}$ for $4 \mathrm{~min}$, then at $94^{\circ} \mathrm{C}$ for $30 \mathrm{~s}, 59^{\circ} \mathrm{C} 30$ $\mathrm{s}, 72^{\circ} \mathrm{C}$ for $1.5 \mathrm{~min}$ for 30 cycles and $72^{\circ} \mathrm{C}$ for $10 \mathrm{~min}$. PCR products were visualized on $1.0 \%$ agarose gel. For Southern blot analysis, genomic DNA was isolated from PCR positive transgenic plants. After digested with BamHI, DNA was blotted onto a nylon membrane positively charged by capillary transfer with $20 \times \mathrm{SSC}$, hybridized with DIG-labeled DNA probe at $58^{\circ} \mathrm{C}$, and washed at high stringency $(2 \times \mathrm{SSC}$, $0.1 \% \mathrm{SDS}$, at $15-25^{\circ} \mathrm{C}$ for $10 \mathrm{~min}$, then $0.5 \times \mathrm{SSC}, 0.1 \% \mathrm{SDS}$ at $65-68^{\circ} \mathrm{C}$ for $30 \mathrm{~min}$ ) (Sambrook and Russell 2001). Immunological detection was according to the protocol of DIG 
DNA Labeling and Detection Kit (Roche). The DIG-labelled DNA probes were made from the pBI-OjBADH-GUS plasmid use the PCR DIG Probe Synthesis Kit (Roche, Cat. No. 1636090). The PCR mixture includes $5 \mu \mathrm{l}$ PCR buffer, $5 \mu 1$ DIG labelling mix, $1 \mu \mathrm{l}$ primer $\mathrm{R}, 1 \mu \mathrm{l}$ primer $\mathrm{F}, 1.25 \mu 1$ template $(10 \mathrm{ng} / \mu \mathrm{l}) .0 .75 \mu \mathrm{l}$ enzyme mix, and $36 \mu 1$ sterile water. The total volume is $50 \mu \mathrm{l}$ and PCR was run by following the manufacturer's instruction.

\section{Northern Blotting}

Leaves of one-year old $O j B A D H$ transgenic tobacco plants were picked for total RNA extraction by TRNzol reagents. The RNA was transferred onto nylon film via high salt $(20 \times \mathrm{SSC})$ solution after electrophoresis in $1 \%$ agarose gel and denatured by $6 \%$ formaldehyde [25]. Northern blotting analysis was performed by using the coding fragment of the $B A D H$ gene as a probe, and labeled with DIG High Prime DNA Labeling and Detection Starter Kit I. Northern blot analysis of the $O$. japonicus $B A D H$ mRNA derived from $O$. japonicus plant 7 days after treated with $400 \mathrm{mmol} / \mathrm{l} \mathrm{NaCl}$ and non-treated control plant was carried out as previously described standard protocol [25], using the coding fragment of the $B A D H$ gene as a probe as above.

\section{Salt Tolerance Analysis}

Salt-tolerance experiments were carried out as described previously $[18,27]$. Transgenic plants grown for three months were subjected to salt-shock treatment, which was administered by watering transgenic plants with $400 \mathrm{mM}$ $\mathrm{NaCl} 4$ times a day for 2 days, and then returned to normal growth conditions [plants were grown in plastic pots filled with a perlite/peatmoss/vermiculite $(1: 1: 1 \mathrm{v} / \mathrm{v})$ mixture located in a greenhouse at $25^{\circ} \mathrm{C}$ with $16 \mathrm{~h}$ of light $\left(50 \mu \mathrm{molm}^{-2} \mathrm{~s}^{-1}\right)$ and $8 \mathrm{~h}$ of dark]. Survival rate was determined 15 days after treatment by dividing the survival plants with the total tested plants for each treatment. We only evaluate the tolerance to salt in the 7 transgenic F0 plants. Experiments were repeated three times, and each replicate consisted of 30-90 plants, data represent the mean \pm SD.

\section{Glycine Betaine Analysis}

The measurement of betaine level was conducted as before $[10,18]$ in three months old tobacco plants, which were with $400 \mathrm{mM} \mathrm{NaCl} 4$ times a day for 2 days, and then returned to normal growth conditions as salt tolerance experiments. Betaine level was measured at 1, 4, 7, 10, and 13 days after salt stress. Experiments were repeated three times, and each replicate consisted of 3-5 plants, data represent the mean $\pm \mathrm{SD}$.

\section{RESULTS}

\section{Isolation the Full-Length cDNA of the $O$. japonicus BADH Gene}

Betaine aldehyde dehydrogenase (BADH) catalyzes the last step (Fig. 1) in the synthesis of the osmoprotectant glycine betaine from choline in higher plants. The fragment of the $O$. japonicus $B A D H$ cDNA, obtained by RT-PCR, was about 1250bp (Fig. 2A), the 5'end is 360bp (Fig. 2B), and the 3 'end is $680 \mathrm{bp}$ (Fig. 2C). Therefore, the full length $B A D H$ cDNA assembled by software DNAMAN was 1785bp (Fig. 2D) with a 63bp for the 5' UTR, a $219 \mathrm{bp}$ for the 3' UTR and a polyA signal-AATTAA. The open reading frame (ORF) was $1503 \mathrm{bp}$, which encodes a 500-amino acid polypeptide. The BADH cDNA sequence of $O$. japonicus was submitted to the GenBank database and the registration number is DQ645888. The nucleotide sequence and its encoding amino acid sequence were shown in Fig. (3). Northern blot analysis of the $O$. japonicus $B A D H$ mRNA derived from $O$. japonicus plant 7 days after treated with $400 \mathrm{mmol} / \mathrm{l}$ $\mathrm{NaCl}$ and non-treated control plant demonstrated that 400 $\mathrm{mmol} / \mathrm{l} \mathrm{NaCl}$ salt stress induced the increase of $O j B A D H$ mRNA (Fig. 2E).

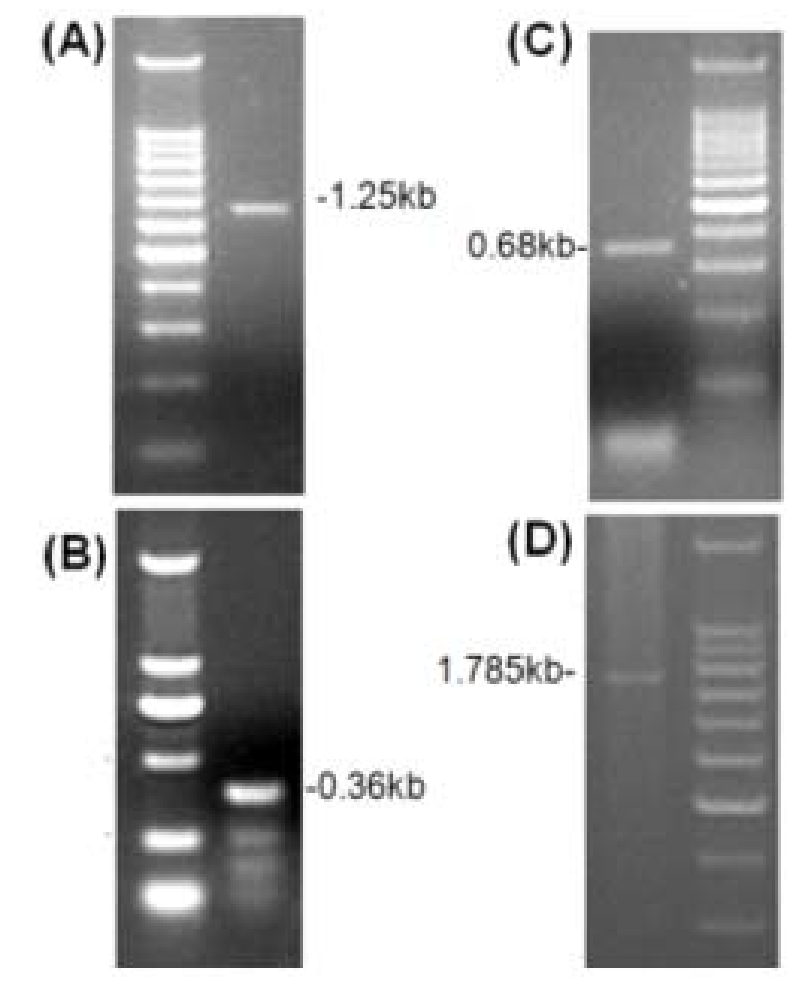

(E)

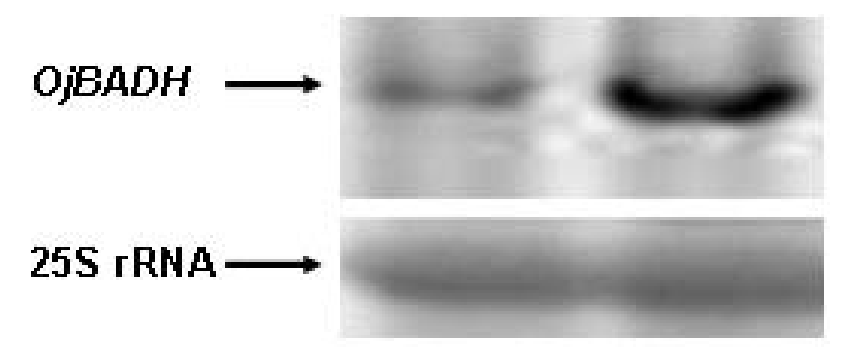

Fig. (2). PCR products of the $B A D H$ gene.

(A) EST of $B A D H$, obtained with degenetrate primers, (B) The 5' end of $B A D H$ and (C) the 3' end of $B A D H$ obtainded with RACE technique. (D) The complete cDNA of the $B A D H$ gene amplified with primers derived from the sequene obtained by means of RACE 5' and 3'. (E) Northern blot analysis of the O. japonicus BADH mRNA derived from $O$. japonicus plant 7 days after treated with $400 \mathrm{mmol} / \mathrm{l} \mathrm{NaCl}$ and non-treated control plant. Low panel: tobacco $25 \mathrm{Sr}$ RNA.

The complete $B A D H$ sequence homology comparison was done between $O$. japonicus and other reported species. The result showed that $O$. japonicus $B A D H$ gene and that of 


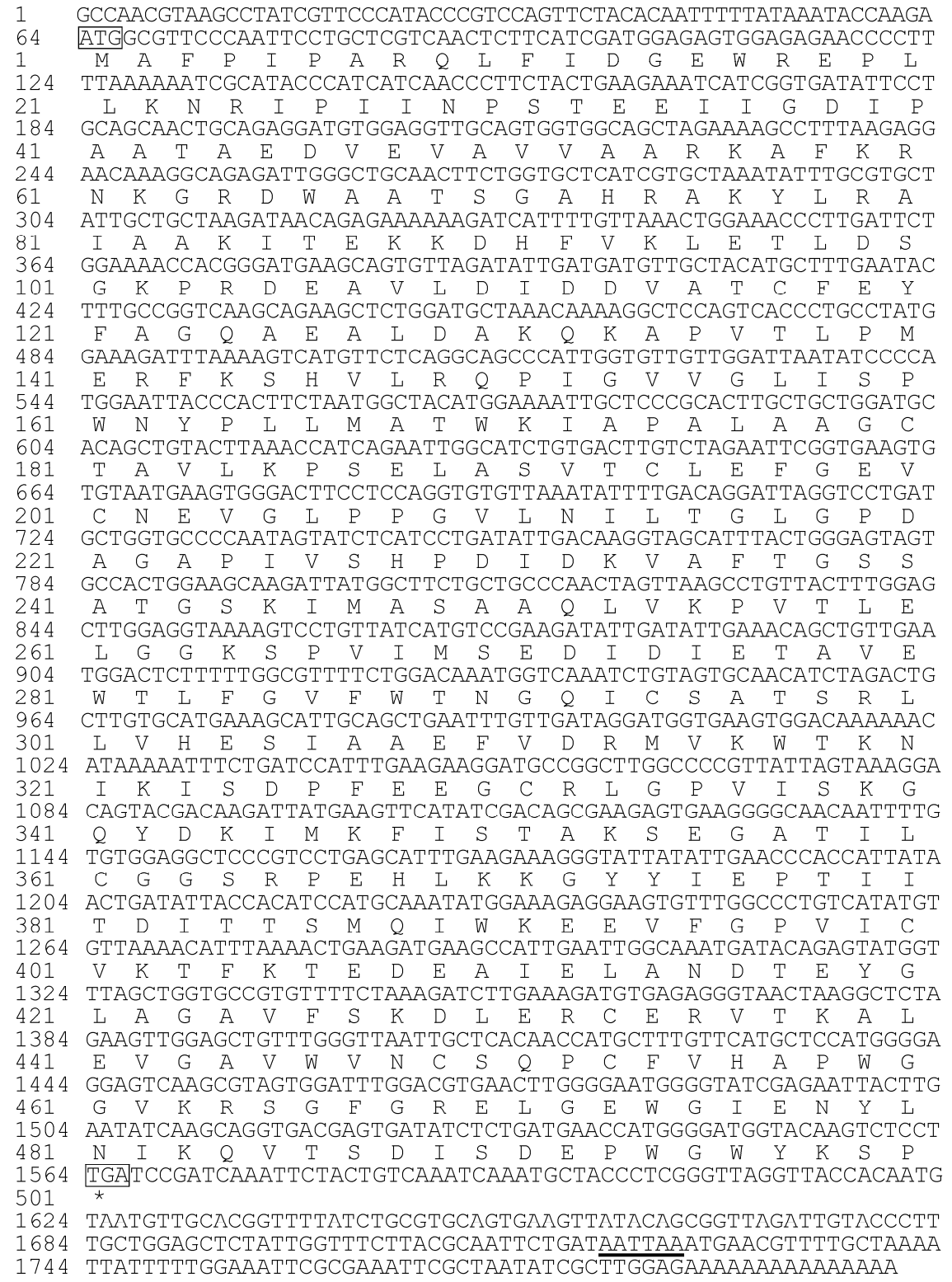

Fig. (3). Nucleotide sequence of the $O$. japonicus $B A D H$ gene. The amino acid sequences are below the nucleotide sequence of the $O$. japonicus BADH gene. Start codon and stop codon are indicated by boxes. The region before the start codon is the 5'UTR. The 3'UTR follows the stop codon. The polyA signal-AATTAA was underlined.

the Chenopodiaceae plants had a high homology. It was as high as $98 \%$ with Atriplex hortensis, $89 \%$ with Spinacia oleracea L. and $86 \%$ with Beta vulgaris. The homology with Suaeda genus plants, rice, Arabidopsis thaliana plants are more than $70 \%$ (Fig. 4). Functional domains of the amino acid sequence encoded by $B A D H$ ORF were analyzed. It included the conservative region of phosphofructokinase, aldehyde dehydrogenase family and glutamy phosphoric acid reductase, which are conserved in other BADH genes derived from Spinacia oleracea L., Beta vulgaris L., Atriplex hortensis Golosk., Hordeum vulgare L., Sorghum bicolor Pers, Amaranthus hypochondriacus L., Avicennia marina (Forsk.)Vierh., Suaeda liaotungensis Kitag., and Atriplex centralasiatica Iljin. These functional domains play important role in salt stress tolerance.

\section{Overexpression of $O j B A D H$ Gene in Tobacco}

To generate transgenic plants, expression vector pBI$O j B A D H-G U S$ was delivered to target issue using a BioRad PDS-1000/He device. Transient GUS expression was 


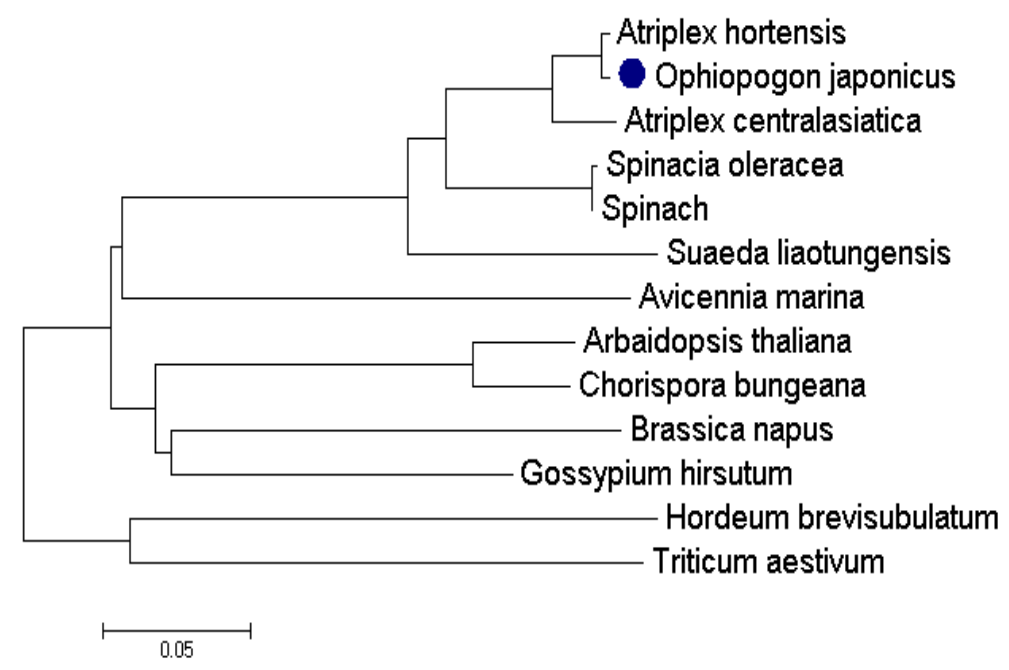

Fig. (4). Phylogenetic tree of $B A D H$ genes includes the $O$. japonicus $B A D H$ gene and $B A D H$ genes from twelve other plant species including Atriplex hortensis (DQ497233.1), Ophiopogon japonicas (DQ645888.1), Atriplex centralasiatica (AE017353.1), Spinacia oleracea (FJ595952.1), Spinach (M31480.1), Suaeda liaotungensis (AF359282.), Avicennia marina (AB043540.1), Arabidopsis thaliana (AY062987.1), Chorispora bungeana (AY804192.1), Brassica napus (AY351634.1), Gossypium hirsutum (AY461804.2), Hordeum brevisubulatum (AY188952.1), Triticum aestivum (AY050316.1). The dot $(\bullet)$ indicates the O.japonicus BADH gene. The scale bar represents the protein distance.

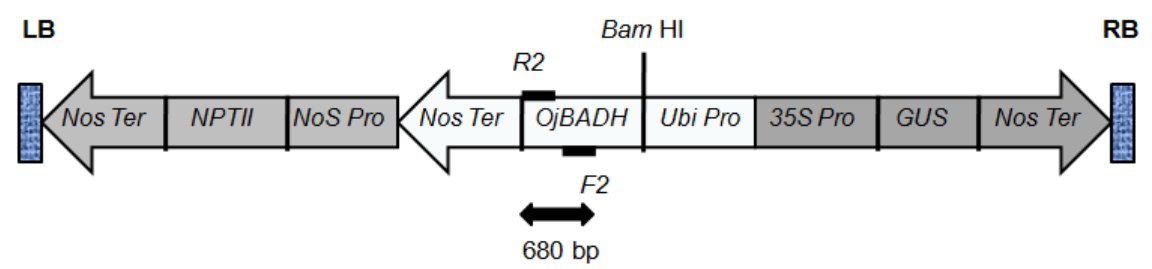

Fig. (5). Linear plasmid map indicating the localization of the different genes (NPTII neomycin phosphotransferase gene, $O j B A D H O$. $j a-$ ponicus betaine aldehyde dehydrogenase gene, GUS $\beta$-glucuronidase), promoters (Nos pro the promoter from nopaline synthase gene, $35 S$ Pro the cauliflower mosaic virus $35 \mathrm{~S}$ promoter, Ubi Pro ubiquitine promoter), terminator (Nos Ter the terminator from nopaline synthase gene), and T-DNA borders ( $L B$ left border, and $R B$ right border). The arrows indicate the translation orientation of the genes. The probe used in Southern blot analysis of transgenic plants is the PCR fragment of $O j B A D H$ amplified using primers R2 and F2, BamHI was used to digest the genomic DNA isolated from transgenic plants, and their positions are indicated immediately above. Binding sites of PCR primers R2 and F2 are shown as black rectangles.

detected $40 \mathrm{~h}$ after particle bombardment (data not shown). Calli at different growth stage were tested for transformation and GUS staining. Calli grown on fresh medium for less than two weeks have high frequency of positive GUS staining (up to $19 \%$ ). Calli grown on fresh medium for more than three weeks have low frequency of positive GUS staining (about $7 \%$ ). The frequency of positive GUS staining calli is about $7-19 \%$. Selection was initiated six days after particle bombardments. Calli were transferred onto the regeneration medium containing $200 \mathrm{mg} / \mathrm{l} \mathrm{kanamycin} \mathrm{for} \mathrm{two} \mathrm{months.} \mathrm{After}$ transgenic shoots were generated on medium containing 200 $\mathrm{mg} / \mathrm{l}$ kanamycin, transgenic shoot clusters were transferred onto kanamycin-free rooting medium to regenerate transgenic plants. Nine putative transgenic lines were obtained and putative transgenic plants were produced from seven of them. Three-month-old putative transgenic plants were used to evaluate by means of PCR, Southern and Northern in tobacco transgenic plants. Transgenic lines were confirmed by PCR (Fig. 6A), Southern blotting (Fig. 6B), and northern blotting analysis (Fig. 6C). Transgenic plants with one copy of the transgene were selected for stress resistant assay.

\section{O. japonicus BADH Gene Improved Salt Tolerance}

For salt tolerance analysis, transgenic tobacco plants were watered with $400 \mathrm{mM} \mathrm{NaCl}$ for $48 \mathrm{~h}$ at room temperature, then return to normal growth condition. The phenotype of WT and transgenic lines after salt stress was shown in Fig. (7A). The transgenic plant has normal stem and leaves and the control has wilted leaves and stop to grow. Under nonstress conditions, transgenic plants have normal stem and leaves as the wild type control. They have the same growth rate. Survival rate was measured 15 days after treatment (Fig. 7B). Stress resistance analysis of $O j B A D H$ transgenic tobacco plants demonstrated the improved salt tolerance under stress of $400 \mathrm{mM} \mathrm{NaCl}$ (Fig. 7B). Survival rate (\%) of transgenic lines (BADH3, BADH6, BADH8, and BADH9) under stress of $400 \mathrm{mM} \mathrm{NaCl}$ has been significantly increased compared to the control (Fig. 7B). Thirty wild type plants were used as control plants and the experiments were 

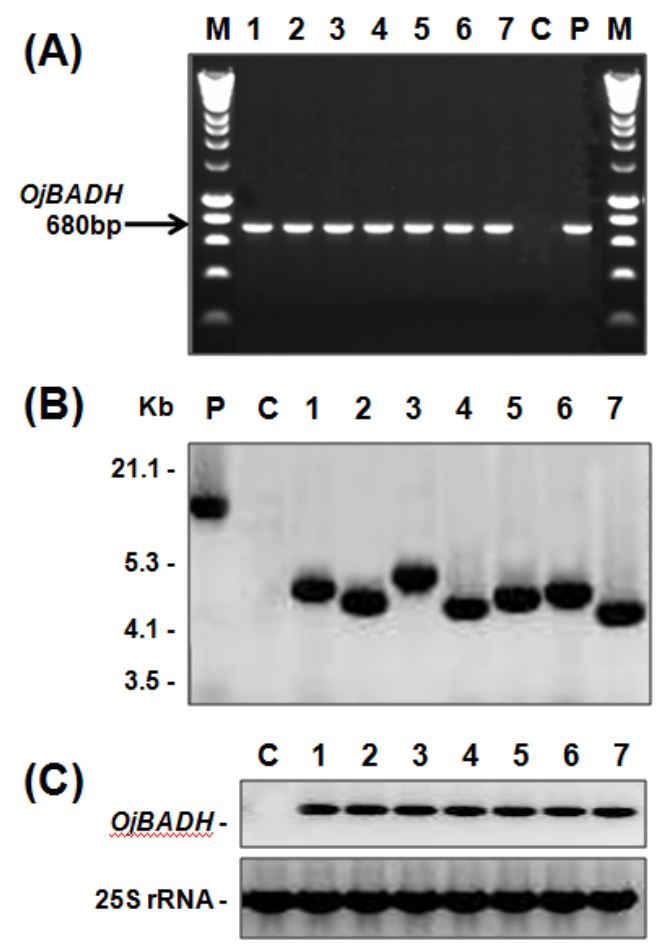

Fig. (6). Overexpression of the $O$. japonicus $B A D H$ cDNA in tobacco.

(A) PCR analysis of transgenic lines using primers R2 and F2 and the predicted 680bp DNA fragments were amplified from 7 different transgenic lines (lanes 1-7: BADH3, BADH6, BADH8, BADH9, BADH15, BADH16, and BADH29). (B) Southern blot analysis of transgenic plants derived from different transgenic lines (lanes 1-7: BADH3, BADH6, BADH8, BADH9, BADH15, BADH16, and BADH29); (C) Northern blot analysis of transgenic plants derived from different transgenic lines (lanes 1-7: BADH3, BADH6, BADH8, BADH9, BADH15, BADH16, and BADH29). Low panel: tobacco 25Sr RNA. The probe used in Southern and northern blot analyses of transgenic plants is the PCR fragment amplified using primers R2 and F2. C: negative control, M: HyperLadder I molecular weight marker, P: positive control (plasmid pBI-OjBADH-GUS).

repeated three times. Measurement of the glycine betaine content demonstrated that the content of glycine betaine was increased by 2-3 fold in transgenic tobacco plants, compared to the control (Fig. 7C). Salt tolerance experiments showed that increased tolerance was conferred by overexpression of $B A D H$ in transgenic tobacco. The $O$. japonicus $B A D H$ gene could be useful to produce salt tolerance transgenic plants.

\section{DISCUSSION}

BADHs (betaine aldehyde dehydrogenases) have been identified in microorganisms [7] and mammalian liver [16, 28] where they act as. osmoregulation agents and aldehyde dehydrogenase E3 isozyme. In plants, BADH converts betaine aldehyde into glycine betaine in some halotolerant plants (Fig. 1). Glycine betaine is an important quaternary ammonium compound that is produced in response to salt and other osmotic stresses in many organisms [7]. The increase in BADH mRNA establishes that stress-induced betaine accumulation in maize involves modulation of the expression of a betaine biosynthesis gene [29]. In this study, northern blot analysis of the $O$. japonicus BADH mRNA derived from $O$. japonicus plant 7 days after treated with 400 $\mathrm{mmol} / \mathrm{l} \mathrm{NaCl}$ and non-treated control plant demonstrated that $400 \mathrm{mmol} / 1 \mathrm{NaCl}$ salt stress induced the increase of $O j B A D H$ mRNA (Fig. 2E). Our results confirmed that $O j B A D H$ mRNA levels change in turfgrass subjected to salt stress. The rise in the level of BADH mRNA in salinized plants could result from stress-enhanced transcription or greater mRNA stability [27, 30]. Such links between salt- or water-stress metabolism and gene expression have rarely been demonstrated for plants, although many osmotic stress-induced plant genes have been reported [31-33].

It has been reported that $B A D H$ gene in plants was included in a small multi-gene family. In barley, there is a small multi-gene family with 2 or 3 members $[18,34]$. Two members of the gene in Sorghum vulgare, Avicennia marina and Atriplex triangularis have been cloned [3, 12, 30]. However, the expression profiles and the position of enzyme protein coding of the members from the $B A D H$ gene family are different. To our knowledge, this is the first report for the isolation, clonation and characterization of the $B A D H$ gene from $O$. japonicus, which is an important turfgrass specie in China. To characterize the function or the $O$. japonicus $B A D H$ gene, a 1,785 bp region of the gene encoding the betaine aldehyde dehydrogenase (BADH) was isolated. We cloned the full length cDNA of the $O$. japonicus $B A D H$ gene into $\mathrm{pBI} 121$ to generate the expression vector $\mathrm{pBI}-O j B A D H$ GUS. The expression vector carrying the $O j B A D H$ gene was delivered into tobacco. After $O j B A D H$ transgenic tobacco plants were produced, transgenic plants were confirmed by polymerase chain reaction and northern hybridization analyses. The results demonstrated that the $B A D H$ gene was integrated into the genome of tobacco (Fig. 6A-C).

Observations on survival rate, rooting development, and relative electronic conductivity (data not shown) suggested that the transgenic plants exhibited tolerance to salt stress. Transgenic plants were examined for tolerance to $\mathrm{NaCl}$ by induced salt stress with $400 \mathrm{mmol} / \mathrm{l} \mathrm{NaCl}$ solution. Fifteen days after treatment, $74-95 \%$ of the transgenic plants survived and grew well, whereas control plants wilted and showed loss of chlorophyll. Only $8.9 \%$ of the control plants survived but gradually died after salt stress. The results of glycine betaine measurement showed that transgenic tobacco plants had increased glycine betaine level in leaves and a higher glycine betaine level was also observed when the transgenic plants were challenged with $\mathrm{NaCl}$. Compared to the control, the betaine levels were enhanced 2-3-fold in transgenic tobacco leaves after treatment with $400 \mathrm{mmol} / \mathrm{l}$ $\mathrm{NaCl}$. These results suggest that overexpression of the $O$. japonicus $B A D H$ gene increased the level of glycine betaine in transgenic tobacco. Because the expression of the $O j B A D H$ cDNA is under the control of the constitutive $35 \mathrm{~S}$ promoter, two to three fold increase in glycine betaine content obtained from both $\mathrm{BADH} 3$ and BADH6 transgenic lines could not due to the increase entirely obtained from the wild type contrl plants (Fig. 7C). For example, glycine betaine content in BADH6 increased from 0.19 to $0.65 \mathrm{mg} / \mathrm{g}$ fresh weight after $7 \mathrm{~d}$, an increase of $0.46 \mathrm{mg} / \mathrm{g}$ fresh weight. However, glycine betaine content in the control increased from 0.02 to $0.26 \mathrm{mg} / \mathrm{g}$ fresh weight after $7 \mathrm{~d}$, an increase of $0.24 \mathrm{mg} / \mathrm{g}$ fresh weight (Fig. 7C). Only part of this rise could be due to the endogenous increase obtained in wild type 


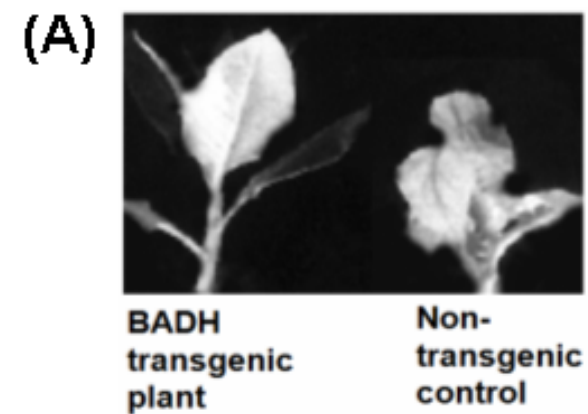

(C)

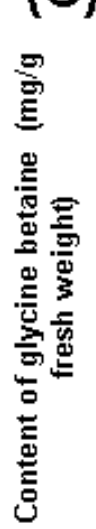

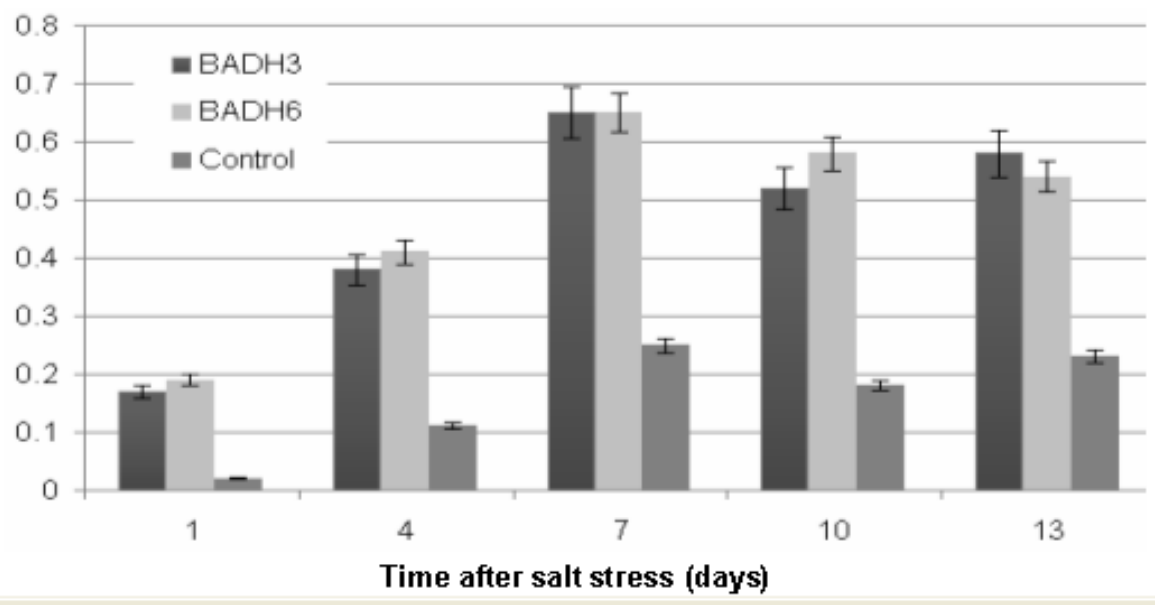

Fig. (7). Stress resistance analysis of BADH tobacco transgenic plants. (A) Phenotype of control plant and transgenic tobacco plant of line BADH3 under stress of $400 \mathrm{mM} \mathrm{NaCl}$. The transgenic tobacco plants were watered with $400 \mathrm{mM} \mathrm{NaCl}$ for $48 \mathrm{~h}$ at room temperature. Pictures were taken 28 days after treatment of salt stress; (B) Survival rate (\%) of transgenic lines (BADH3, BADH6, BADH8, and BADH9) under stress of $400 \mathrm{mM} \mathrm{NaCl}$, survival rate was measured 15 days after treatment of salt stress. (C) Glycine betaine content of transgenic tobacco plants derived from transgenic lines BADH3 and BADH6.

plants, but clearly this rise is insufficient to explain the marked differences observed in the transgenic plants. Therefore, there are other mechanisms could be involved. Our results suggest that the $O$. japonicus $B A D H$ gene can be a useful source for genetic engineering of salt tolerance in tobacco, probably also in other plant species.

\section{ACKNOWLEDGEMENTS}

This work was supported by a grant from the Chinese Ministry of Agriculture, a grant from National Transgenic Plant Research and Application Program (J2002-B-006), and a grant from China 21 Century Talent Research Scientist Program.

\section{ABBREVIATIONS}

$\mathrm{BADH}=$ Betaine aldehyde dehydrogenase

RT-PCR = Reverse Transcriptase-Polymerase Chain Reaction

RACE $=$ Rapid Amplification of cDNA Ends

\section{REFERENCES}

Chen THH, Murata N. Enhancement of tolerance of abiotic stress by metabolic engineering of betaines and other compatible solutes. Curr Opin Plant Biol 2002; 5: 250-7.

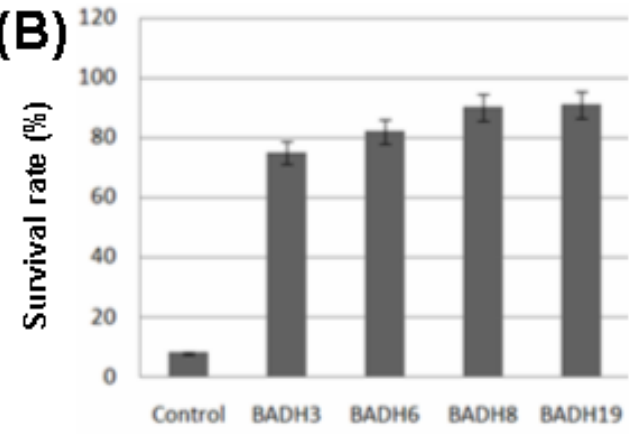

Transgenic lines 
[12] Hibino T, Meng YL, Kawamitsu Y, et al. Molecular cloning and function characterization of two kinds of betaine-accumulating mangrove Avicennia marina (Forsk.) Vierh. Plant Mol Biol 2001; 45: 353-63.

[13] Ishitani M, Arakawa K, Mizuno K, Kishitani S, Takabe T. Betaine aldehyde dehydrogenase in the Gramineae: levels in leaves of both betaine-accumulating and non-accumulating plants. Plant Cell Physiol 1993; 34: 493-5.

[14] Zhang Y, Yin H, Li D, Zhu W, Li Q. Functional analysis of $B A D H$ gene promoter from Suaeda liaotungensis K. Plant Cell Rep 2008; 27: 585-92.

[15] McCue K, Hanson AD. Salt-inducible betaine aldehyde dehydrogenase from sugar beet cDNA cloning and expression. Plant Mo1 Biol 1992; 18: 1-11.

[16] Chern MK, Pietruszko T. Human aldehyde dehydrogenase E3 isozyme is a betaine aldehyde dehydrogenase. Biochem Biophys Res Commun 1995; 213: 561-8.

[17] Sheikh S, Ni L, Hurley TD, Weiner H. The potential roles of the conserved amino acids in human liver mitochondrial aldehyde dehydrogenase. J Biol Chem 1997; 272: 18817-22.

[18] Ishitani M, Nakamura M, Han SY, Takabe T. Expression of the betaine aldehyde dehydrogenase gene in barley in response to osmotic stress. Plant Mo1 Biol 1995; 27: 307-15.

[19] Jia GX, Zhu Z, Chang F, Li Y. Transformation of tomato with the $B A D H$ gene from Atriplex improves salt tolerance . Plant Cell Rep 2002; 21: 141-6.

[21] Kishitani S, Watanabe K, Yasuda S, Arakawa K, Takabe T. Accumulation of glycinebetaine during cold acclimation and freezing tolerance in leaves of winter and spring barley plants. Plant Cell Environ 1994; 17: 89-95.

[20] Ladyman AR, Hitz WD, Hanson AD. Translocation and metabolism of glycine betaine by barley plants in relation to water stress. Planta 1980; 150: 191-6.

[22] Lerma C, Rich PJ, Ju GC, Yang W-J, Hanson AD, Rhodes D. Betaine deficiency in maize: complementation tests and metabolic basis. Plant Physiol 1991; 95: 1113-9.

[23] Li PH, Liu ZX, Fu XP, Wu R, Guo JH, Xie QG. cDNA cloning of FMDV structural protein VP2-3-1 gene and its prokaryotic expression. Chin J Vet Sci 2006; 26: 232-4.
[24] Wu W, Su Q., Xia XY, Wang Y, Luan YS, An LJ. The Suaeda liaotungensis kitag betaine aldehyde dehydrogenase gene improves salt tolerance of transgenic maize mediated with minimum linear length of DNA fragment. Euphytica 2007; 159: 17-25.

[25] Sambrook J, Russell DW. Molecular cloning: a laboratory manual. $3^{\text {rd }}$ ed. New York: Cold Spring Harbor Laboratory Press 2001.

[26] Rathinasabapathi B, McCue KF, Gage DA, Hanson AD. Metabolic engineering of glycine betaine synthesis: plant betaine dehydrogenases lacking typical transit peptides are targeted to tobacco chloroplasts where they confer betaine aldehyde resistance. Planta 1994; 193: 155-62.

[27] Weretilnyk EA, Hanson AD. Molecular cloning of a plant betainealdehyde dehydrogenase, an enzyme implicated in adaptation to salinity and drought. Proc Natl Acad Sci USA 1989; 87: 2745-9.

[28] Yoshida A, Rzhetsky A, Hsu LC, Chang C. Human aldehyde dehydrogenase gene family. Eur J Biochem 1998; 251: 549-57.

[29] Yang W-J, Nadolska-Orczyk A, Wood KV, et al. Near-isogenic lines of maize differing for glycinebetaine. Plant Physiol 1995; 107: 621-30

[30] Wood AJ, Saneoka H, Rhodes D, Joly RJ, Goldsbrough PB. Betaine aldehyde dehydrogenase in sorghum (Molecular Cloning and Expression of Two Related Genes). Plant Physiol 1996; 110: 13018.

[31] Trossat C, Rathinasabapathi B, Hanson AD. Transgenically expressed betaine aldehyde dehydrogenase efficiently catalyzes oxidation of dimethylsulfoniopropion-aldehyde and v-aminoaldehydes. Plant Physiol 1997; 113: 1457-61.

[32] Weretilnyk EA, Bednarek S, McCue KF, Rhodes D, Hranson AD. Comparative biochemical and immunological studies of the glycine betaine synthesis pathway in diverse families of dicotyledons. Planta 1989; 178: 342-52.

[33] Valenzuela-Soto EM, Munoz-Clares RA. Purification and properties of betaine aldehyde dehydrogenase extracted from detached leaves of Amaranthus hypochondriacus $\mathrm{L}$ subjected to water deficit. J Plant Physiol 1994; 143: 145-52.

[34] Weigel P, Weretilnyk EA, Hanson AD. Betaine aldehyde oxidation by spinach chloroplasts. Plant Physiol 1986; 82: 753-9.

(c) Liu et al.; Licensee Bentham Open.

This is an open access article licensed under the terms of the Creative Commons Attribution Non-Commercial License (http://creativecommons.org/licenses/by-nc/3.0/) which permits unrestricted, non-commercial use, distribution and reproduction in any medium, provided the work is properly cited. 